\title{
Preliminary Evaluation of Altitude Scaling for Turbofan Engine Ice Crystal Icing
}

\author{
Jen-Ching Tsao
}

Ohio Aerospace Institute, Cleveland, $\mathrm{OH}$

\author{
Supported by \\ NASA Advanced Air Transport Technology Project
}

\author{
Aviation 2017 \\ Denver CO, 5-9 June 2017
}




\section{Outline}

- Introduction

- Thermodynamic Model

- Key Parameters Governing The IC Accretion Inside an Engine LPC

- Current Challenges for Scaling Consideration

- In PSL-3 (a direct connect test facility)

- A Simplified Approach for Altitude Scaling with LF11

- Matching Similar Engine Icing Risk Parameters

- Using Calibrated COMDES to Identify Scale Test Conditions

- Preliminary Evaluation Results

- Conclusion 


\section{Introduction}

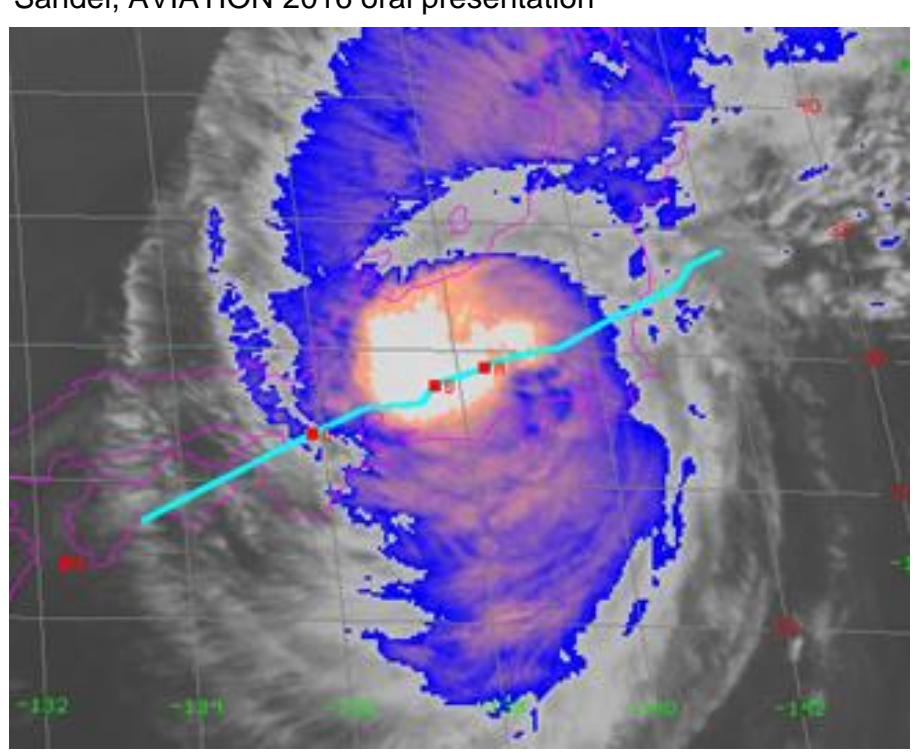

- Ice crystal icing in jet engines - known factor to cause power-loss events and compressor blade damage

- The AC 20-147A was released in Oct. 2014 for App. D of part 33 - comparative analysis (33.68)

- NASA latest technology challenge on Engine lcing is to develop/improve/mature engineering model tools (both experimental and computational) to enable analysis of IC icing effects on current and future $\mathrm{N}+2 / \mathrm{N}+3$ propulsion systems -

1. PSL-3 + Engine Icing Test Methods + Scaling

2. NPSS, COMDES, LEWICE3D, Glenn HT

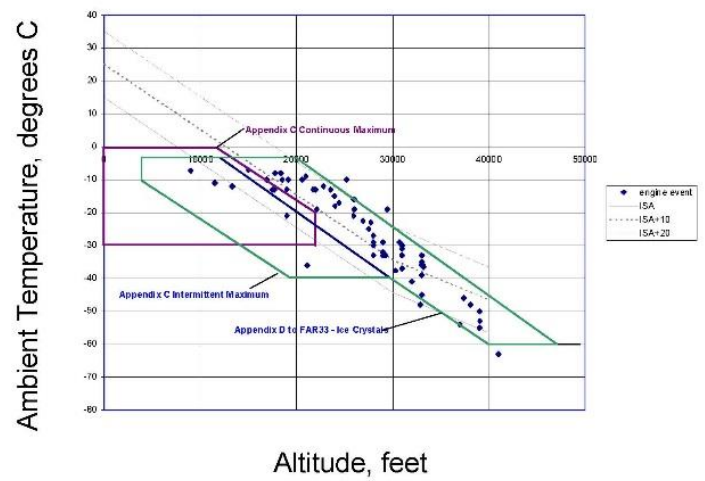




\section{Thermodynamic Model} schematics
Get these conditions from PSL tests data, COMDES, Glenn-HT, LEWICE 3D

\section{Upstream Conditions}

Concentration Factor $\left\{\begin{array}{l}(\mathrm{LWC}, \mathrm{MVD})_{\mathrm{t}} \\ (\mathrm{IWC}, \mathrm{MMD})_{\mathrm{t}}\end{array}\right]$ Melt Ratio

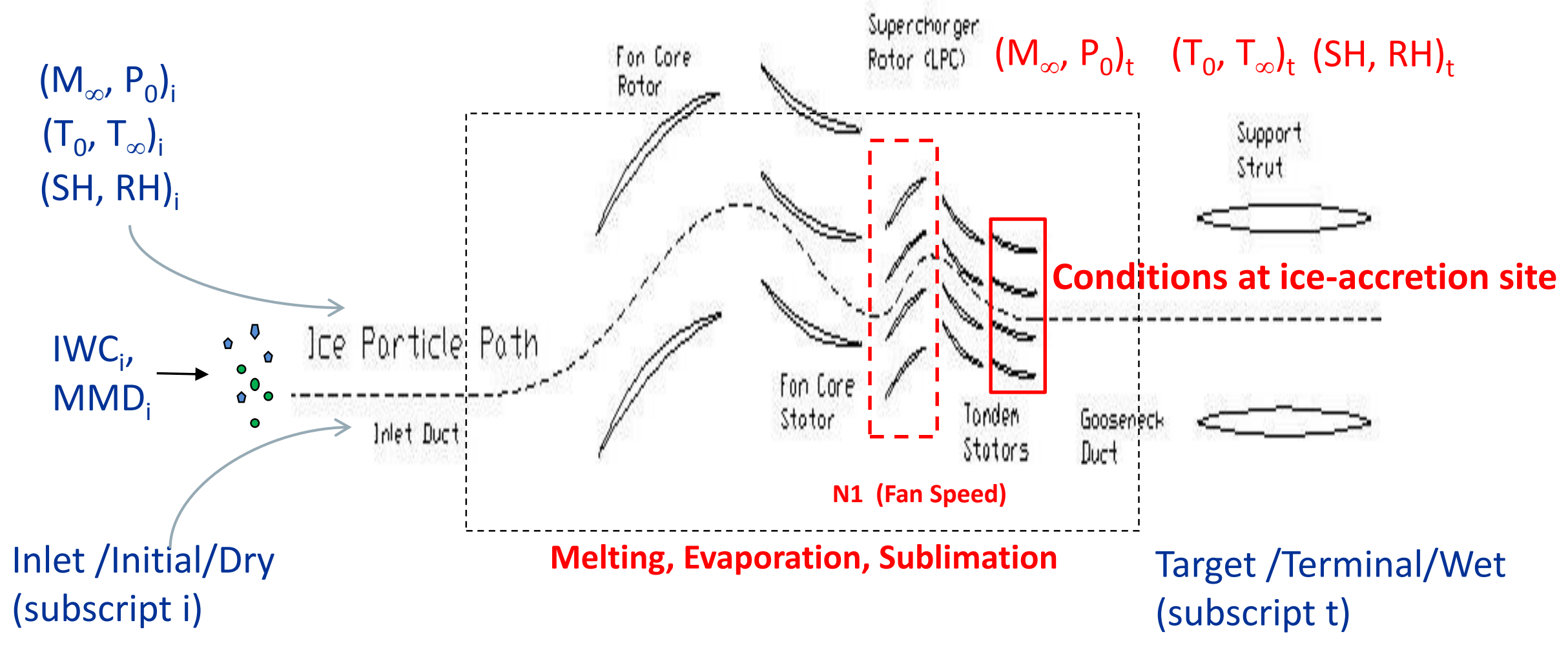




\section{Thermodynamic Model}

stagnation melting fraction

\section{Need conditions at local accretion site}

surface ice growth $\propto\left(1-m_{0}\right) \equiv f\left(I W C / \rho_{\infty}, T_{w b, 0}, M R, N 1, M_{\infty}, h_{c}, \beta_{0}, n_{l o s s, 0}\right)$

\section{The model provides a theoretical base to understand ICI physics}




\section{Current Challenges for Scaling Consideration} in PSL-3

Constraints:

1. No correlation tables or curve-fits were readily available to obtain local IWC, MMD, $T_{w b}, M R, h_{c}, \beta_{0}$ and $n_{\text {loss }, 0}$ for this LF11 engine,

- ICl physics fundamental studies - empirical models and validation data

- $\quad$ Glenn HT simulation $-h_{c}$ (to be presented in Aviation 2017)

- LEWICE3D simulation - $\beta_{0}, I W C, M M D, M R, n_{\text {loss }, 0}$

2. $P S L$ has very limited calibration region of fully glaciated ice particle cloud in terms of (IWC, MMD) range at different altitude and ISA settings
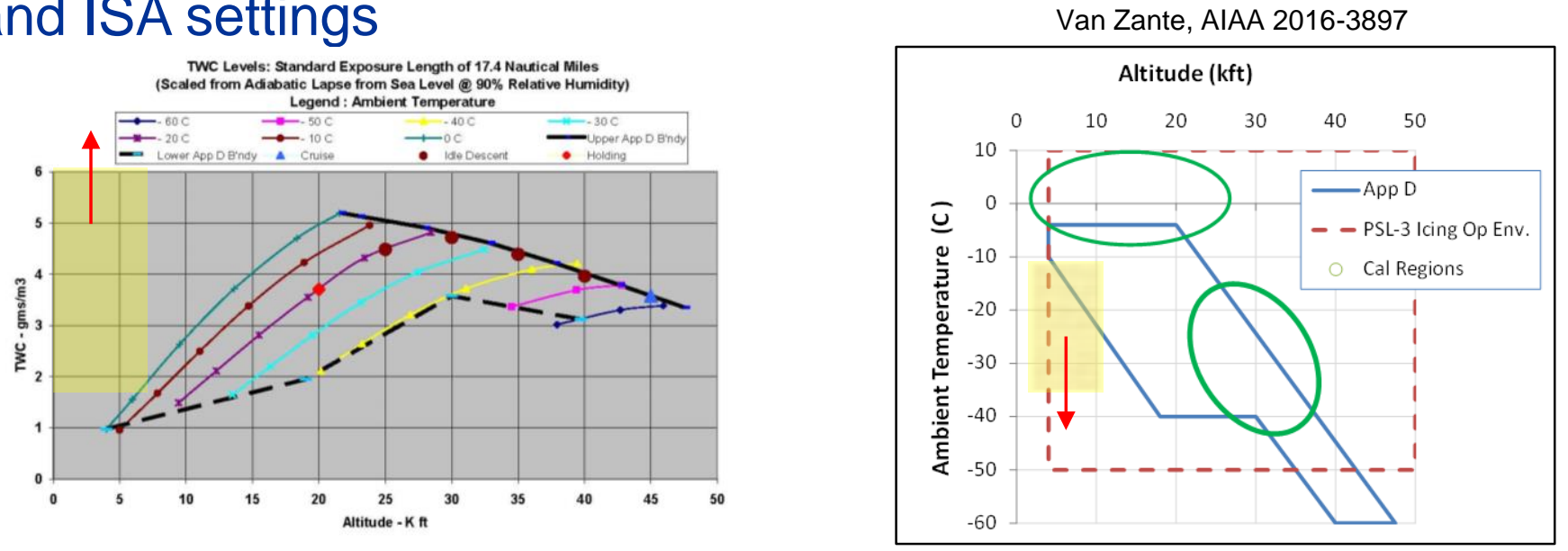

Do what we can with what we have now 


\section{A Simplified Approach for Scaling with LF11}

This simplified altitude scaling approach utilizes

1) A LF01/LF11 calibrated COMDES (Veres, AIAA 2016-3895) code to determine the lower altitude scale condition with similar engine IC icing risk by matching the following three icing parameters at LF11 $2^{\text {nd }}$ exit guide vane trailing edge location

1. local static wet bulb temperature $T_{\text {wbs }}$

2. local IC melt ratio of a prescribed smaller particle size $(5 \mu \mathrm{m})$

3. engine fan face IWAR (i.e. the non-dimensional ice water content $\left.=I W C / \rho_{\infty} \equiv I W C^{*} Q / \dot{m}\right)$

while best maintaining similar fan-core/LPC operation characteristics

2) A parametric sweep of $I W C, M M D, T_{P L}$ and $N 1$ around each lower altitude scale condition to better understand the ice accretion and engine icing effects characteristics - help evaluate how similarly the reference IC icing being simulated

\section{This is an effective process with conservatism consideration}




\section{Preliminary Evaluation Results}

LF11 Test Data

- Match Key LF01 Test Points

- Does LF11 behave like LF01? What does accretion look like at these key points?

- Replicated FLT850 Full Rollback, Rdg 93 Reference Condition

- FLT850 TWC Sweeps: 0.5, 1.0, 1.5, 2.0, 2.5, $5.63 \mathrm{~g} / \mathrm{m3}$

- FLT850 MMD Sweeps: 19, 43, 80um

- Revenue Service Points (Sensitivity study of MMD, N1, Tamb, TWC)

- Understand ice accretion location and sensitivity to varying parameters.

- FLT850 varied N1, Tamb

- Altitude Investigation-Sensitivity study of MMD, N1, Tamb, TWC

- Understand icing at varying altitudes ranging from $35 \mathrm{~K}$ to $5 \mathrm{~K}$.

- Low Alt 5K ft investigation (TWC, Tamb, N1, MMD)
- COMDES \& Scaling, suggested RB conditions - Rdgs 406, 416, 418-424 Identify min IWC threshold $\longrightarrow$ Scale Condition

\section{Better understand IC icing and its effect at ref / scale conditions}




\section{Preliminary Evaluation Results}

$5 \mathrm{~K} \mathrm{ft}$ scale test conditions

\begin{tabular}{|c|c|c|c|c|c|c|c|c|c|c|c|c|c|c|c|c|}
\hline $\begin{array}{c}\text { Escort } \\
\text { Rdg\# }\end{array}$ & $\begin{array}{l}\text { Alt } \\
\text { (kft) }\end{array}$ & $N 1^{*}$ & $\mathbf{M}_{\mathrm{amb}}$ & $\begin{array}{c}\mathrm{T}_{\mathrm{amb}} \\
\left.{ }^{\circ}{ }^{\circ} \mathbf{C}\right)\end{array}$ & $T_{\mathrm{pl}}^{*}$ & $\begin{array}{l}I_{W C_{1}} \\
\left(\mathbf{g} / \mathbf{m}^{3}\right)\end{array}$ & $\begin{array}{c}\mathrm{MMD}_{1} \\
(\mu \mathrm{m})\end{array}$ & $M^{*}{ }_{f f}$ & IWAR & $\begin{array}{c}\mathrm{T}_{\text {wbs, }} \\
\text { EGV2 } \\
\left.\mathrm{TE}^{\circ} \mathrm{C}\right) \\
\left({ }^{\circ} \mathrm{C}\right)\end{array}$ & $\begin{array}{c}T_{\text {surf, }} \\
\text { EGV2, } \\
20 \text { s, avg } \\
\left({ }^{\circ} \mathrm{C}\right)\end{array}$ & $\begin{array}{l}\text { MR } \\
\text { EGV2 } \\
\text { TE }\end{array}$ & $\begin{array}{c}\text { RH } \\
\text { EGV2 TE } \\
(\%)\end{array}$ & $\mathbf{W}_{\text {cor }}^{*}$ & $\mathbf{N} 1^{*}{ }_{\text {cor }}$ & CRB \\
\hline 93 & 28.9 & 1.00 & 0.52 & -30.0 & 1.000 & 2.3 & 23 & 1.00 & 5.05 & -1.32 & 2.96 & 0 & 7.9 & 1.00 & 1.06 & $\begin{array}{c}Y \\
\text { (69s) }\end{array}$ \\
\hline 406 & 4.89 & 0.95 & 0.19 & -20.8 & 0.994 & 5.4 & 24 & 1.05 & 4.51 & -1.48 & 3.68 & 0 & 10.6 & 1.03 & 1.01 & $\underset{\text { (close) }}{\mathrm{N}}$ \\
\hline 416 & 4.86 & 0.95 & 0.19 & -26.4 & 0.971 & 6.4 & 18 & 1.07 & 5.19 & -5.26 & 1.79 & 0 & 10.0 & 1.05 & 1.02 & $\begin{array}{c}\mathrm{Y} \\
\text { (393s) }\end{array}$ \\
\hline
\end{tabular}

1. Red colored number comes from COMDES calculation

2. Black colored number comes from PSL-3 measurement

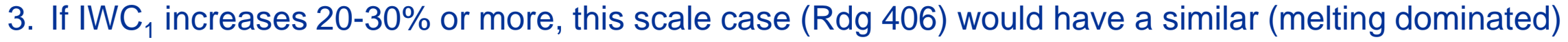
type of CRB as the reference case (Rdg 93) 


\section{Preliminary Evaluation Results}

LF11 Instrumentation (Goodwin, AIAA 2016-3892)

\section{LF11 Special Instrumentation}

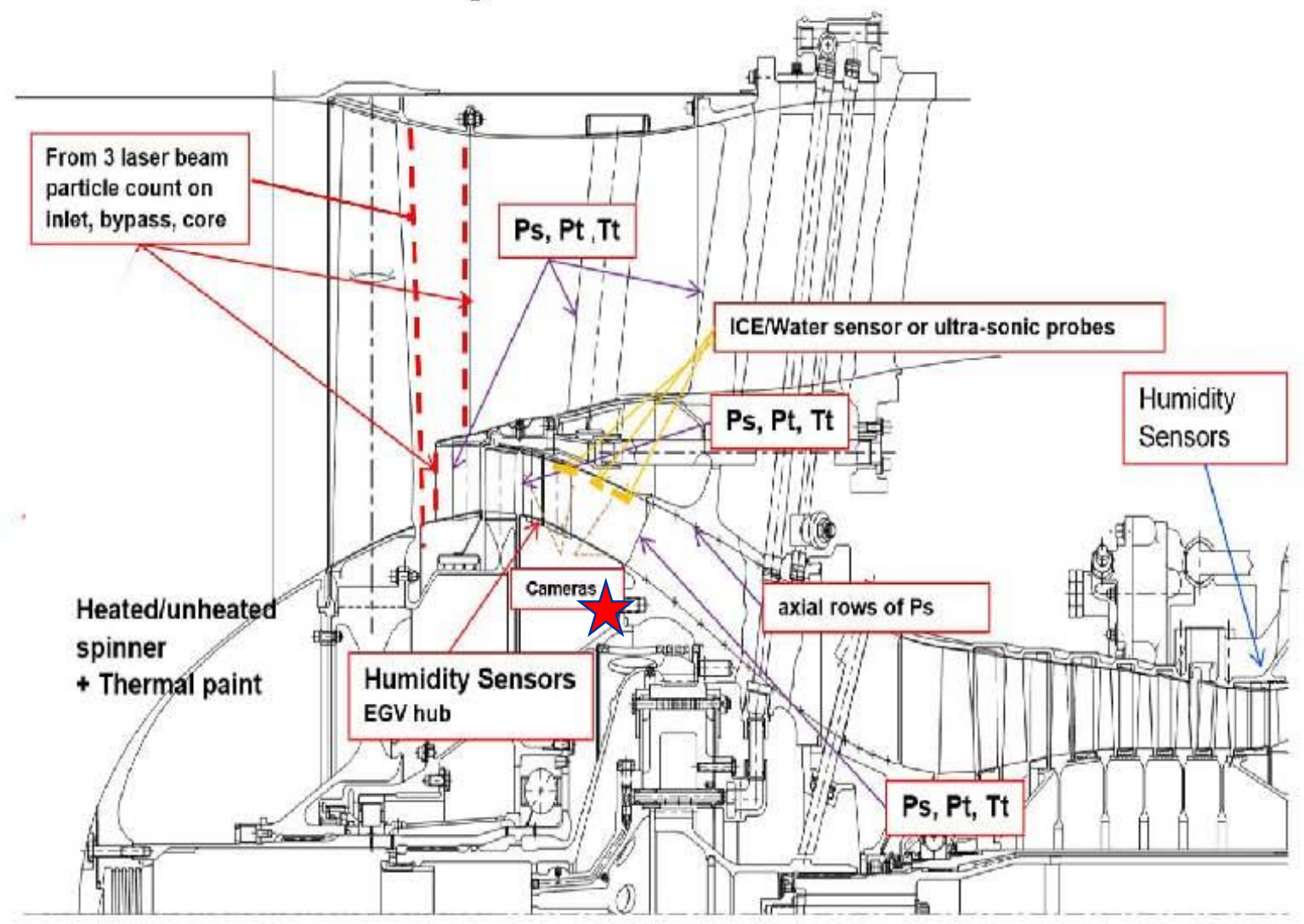

\footnotetext{
All LF01 Instrum. Duplicated, Plus These Addional Honeywell
} 


\section{Preliminary Evaluation Results}

LF11 Camera (Goodwin, AIAA 2016-3892)

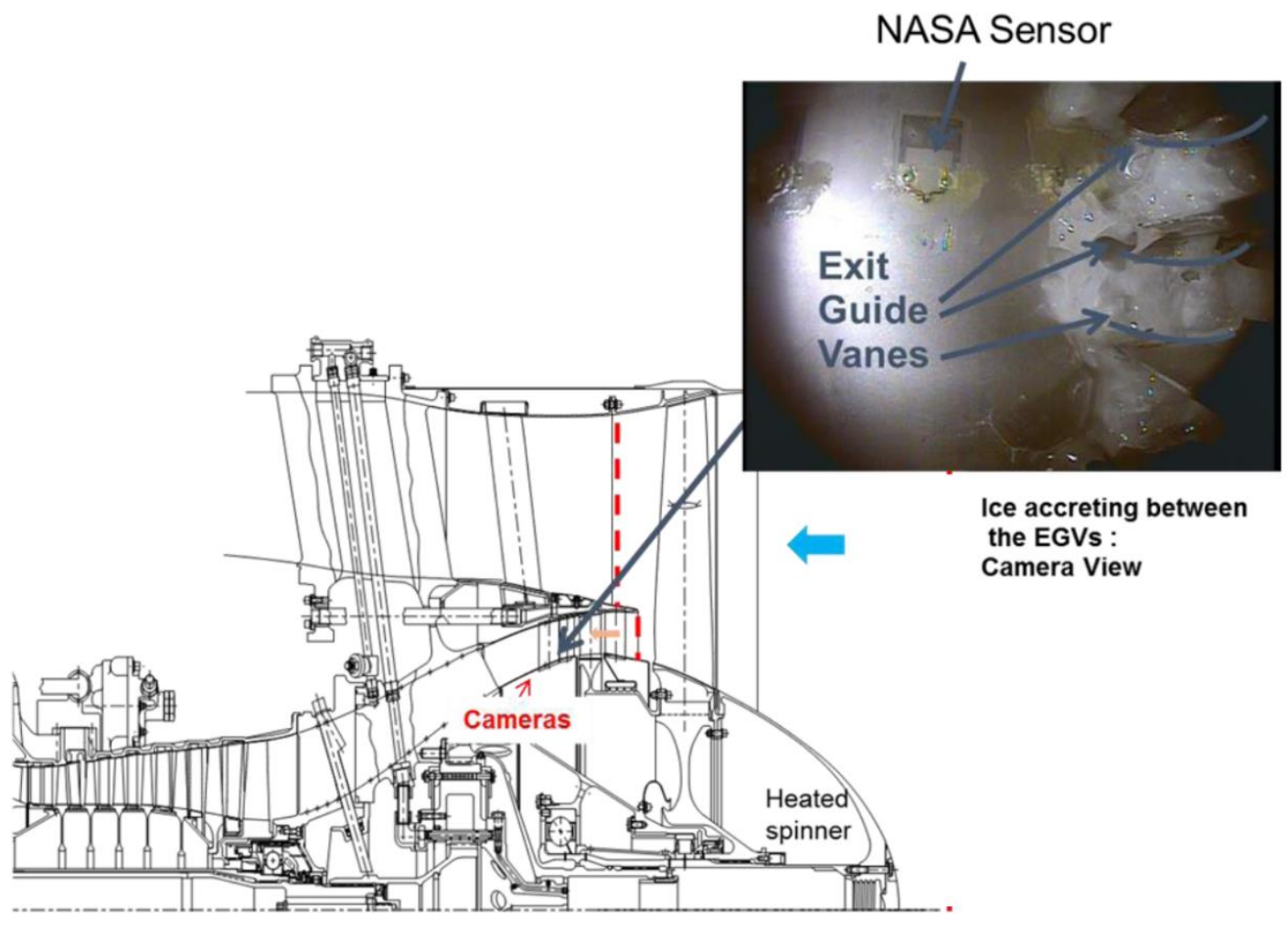

Figure 8. Typical Internal Camera Location

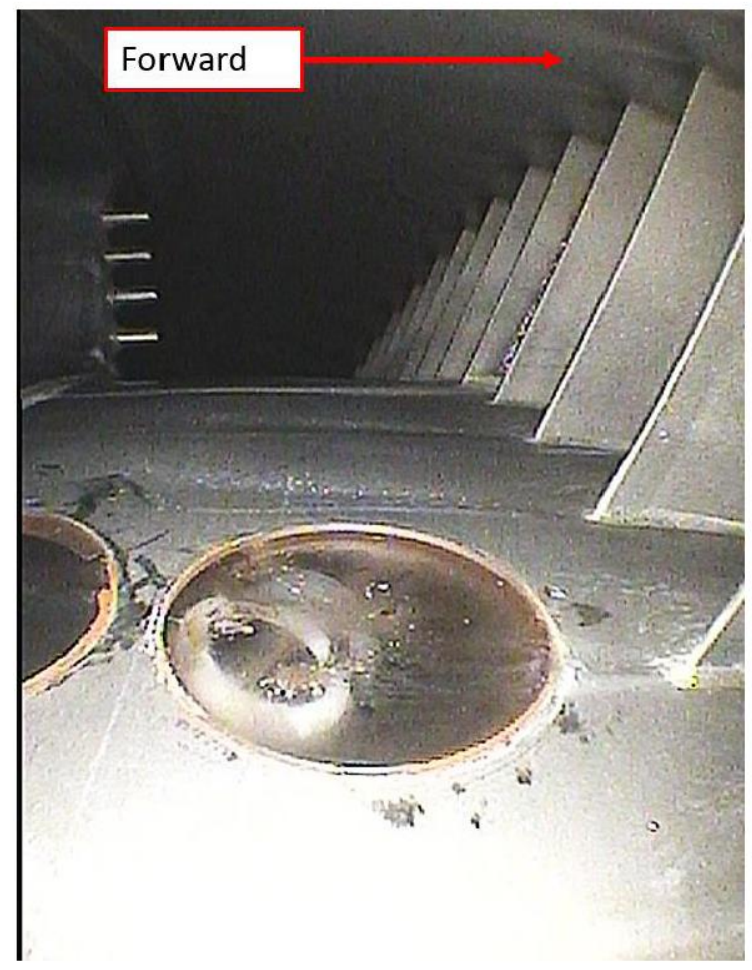

Figure 10. Borescope View of Camera and Aft Edges of EGV,

With Total Probes in the Far Upper Left 


\section{Preliminary Evaluation Results}

\section{Traces of ice buildup/shed \& runback on LPC/HPC}

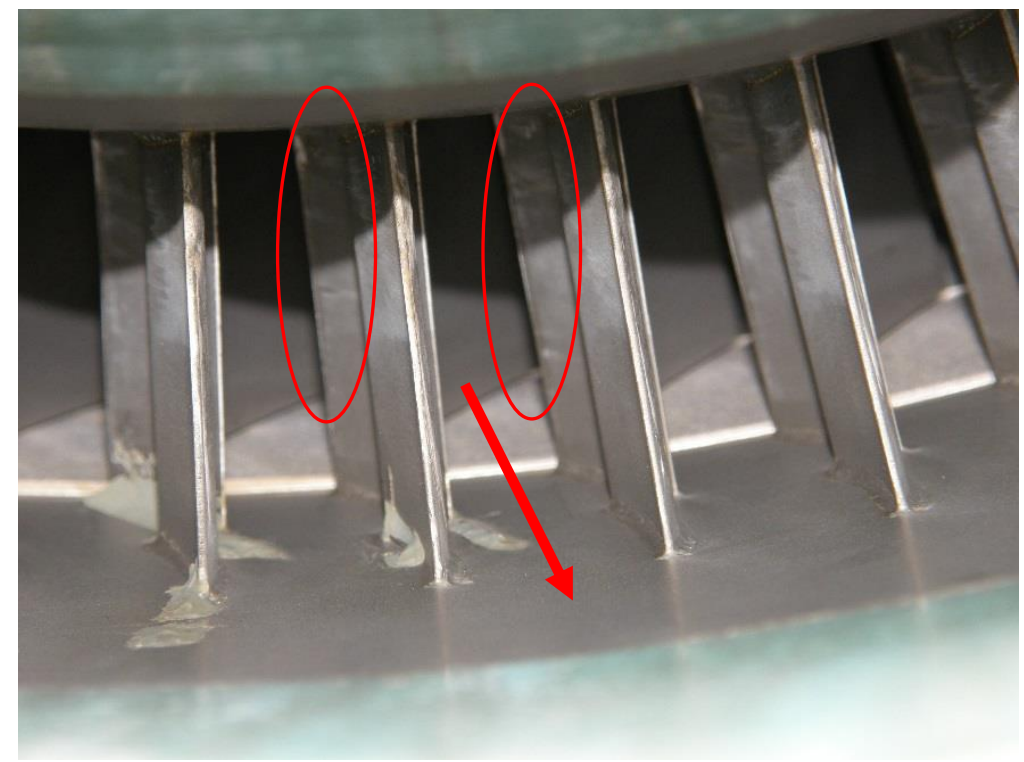

Ice/water trace on leading edge and surface of LP EGVs

(LF11 post-test teardown picture)

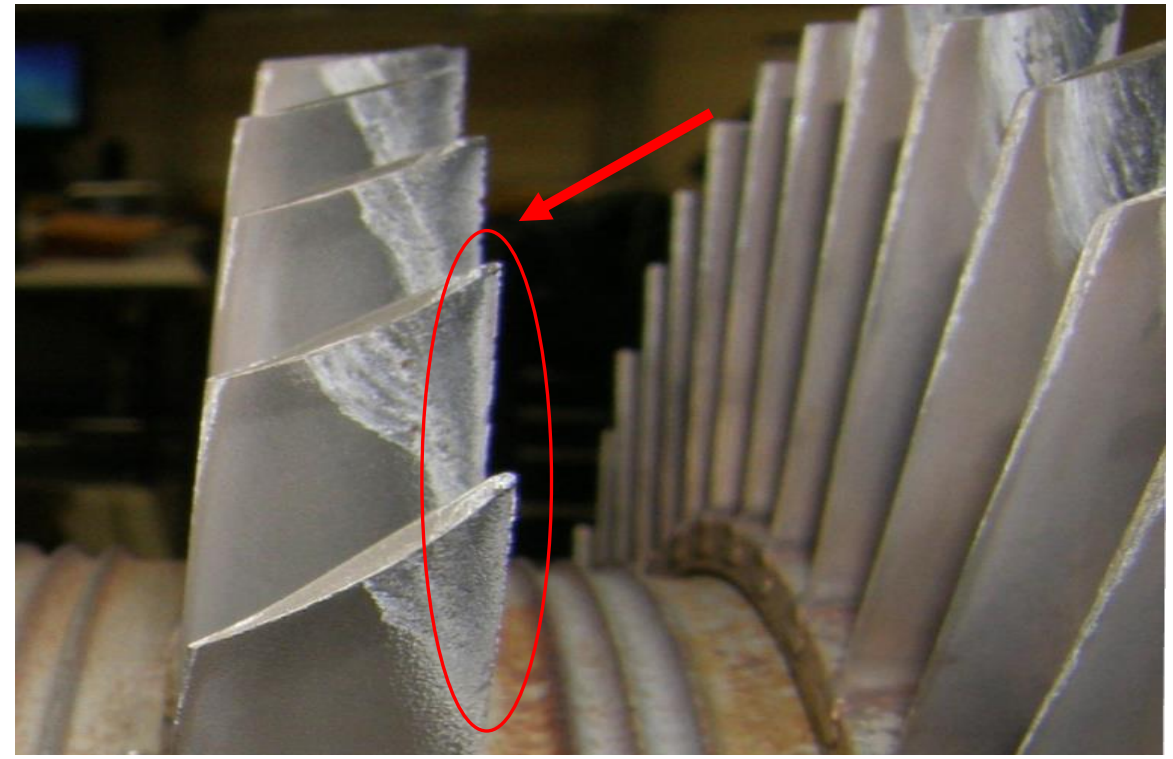

Mineral deposits on leading edge and surface of HP axial rotors (Walker, AIAA 2016-3893)

Need better ice shape characterization to help us understand what features impact engine performance the most!

"How much detail is good enough ?" 


\section{Preliminary Evaluation Results}

\section{Ref FLT850 EGV2 TE ice buildup video (Rdg 93, Cam6, x8)}

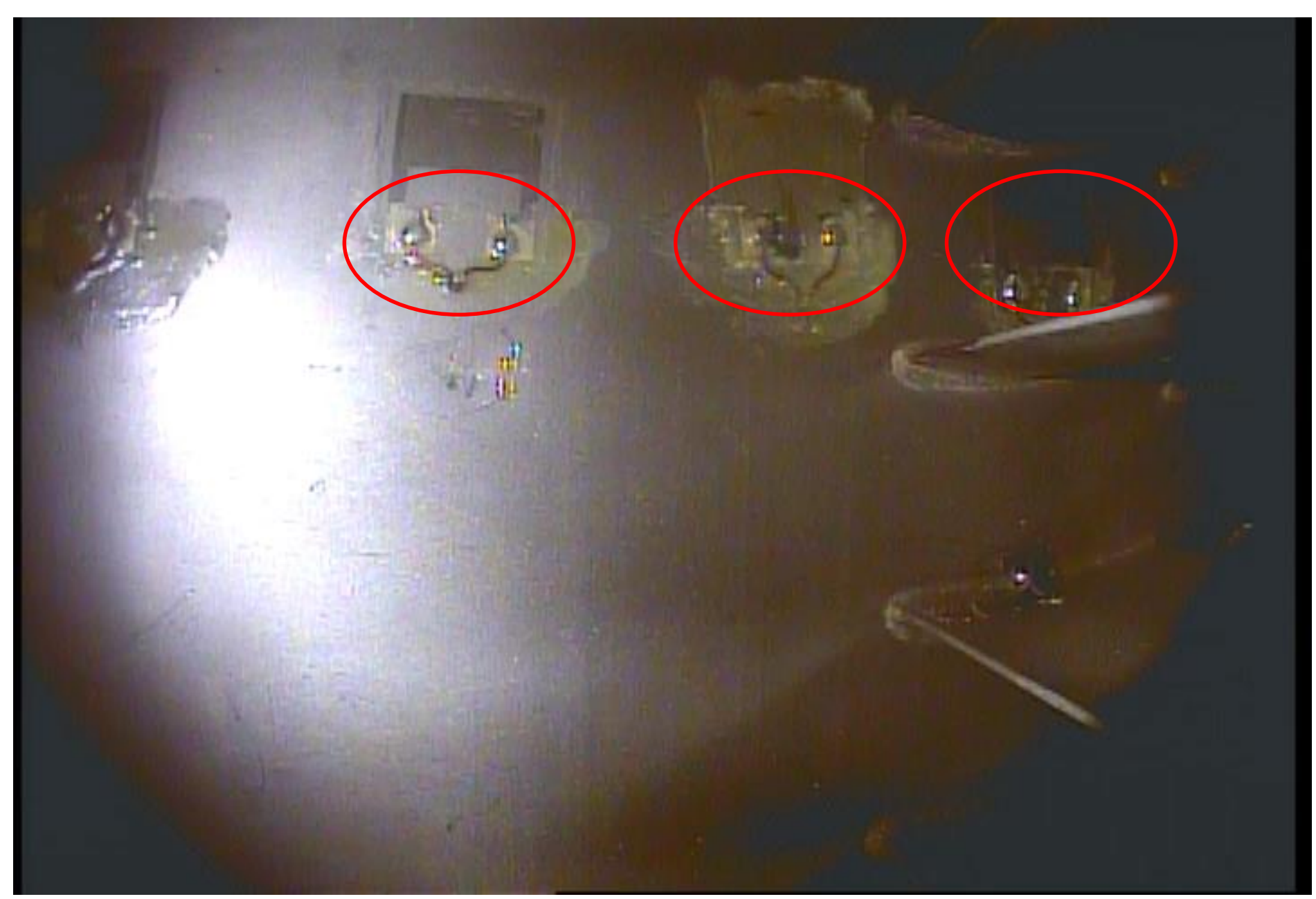

Alt $=28.9 \mathrm{kft} ; \mathrm{M}_{\mathrm{ftt}}=0.52 ; \mathrm{T}_{\mathrm{amb}}=-30^{\circ} \mathrm{C} ; \mathrm{Std}-23 \mu \mathrm{m}, 2.3 \mathrm{~g} / \mathrm{m}^{3} ;$ Full RB 


\section{Preliminary Evaluation Results}

5K scale case, EGV2 TE ice buildup video (Rdg 406, Cam6, x8)

\section{I321: $01: 48: 32.1453$}

Alt $=4.89 \mathrm{kft} ; \mathrm{M}_{\mathrm{flt}}=0.19 ; \mathrm{T}_{\mathrm{amb}}=-20.8^{\circ} \mathrm{C} ; \operatorname{Mod} 1-24 \mu \mathrm{m}, 5.41 \mathrm{~g} / \mathrm{m}^{3} ; \mathrm{NRB}$ (but close) 


\section{Preliminary Evaluation Results}

$5 \mathrm{~K}$ scale case, EGV2 TE ice buildup video (Rdg 416, Cam6, x8)

\section{$1321: 03: 43: 00.6907$}

Alt $=4.86 \mathrm{kft} ; \mathrm{M}_{\mathrm{ftt}}=0.19 ; \mathrm{T}_{\mathrm{amb}}=-26.4^{\circ} \mathrm{C} ; \mathrm{Std}-18 \mu \mathrm{m}, 6.36 \mathrm{~g} / \mathrm{m}^{3} ; 6: 33 \mathrm{CRB}$ 


\section{Preliminary Evaluation Results}

LF11 Fan-core \& LPC Operation

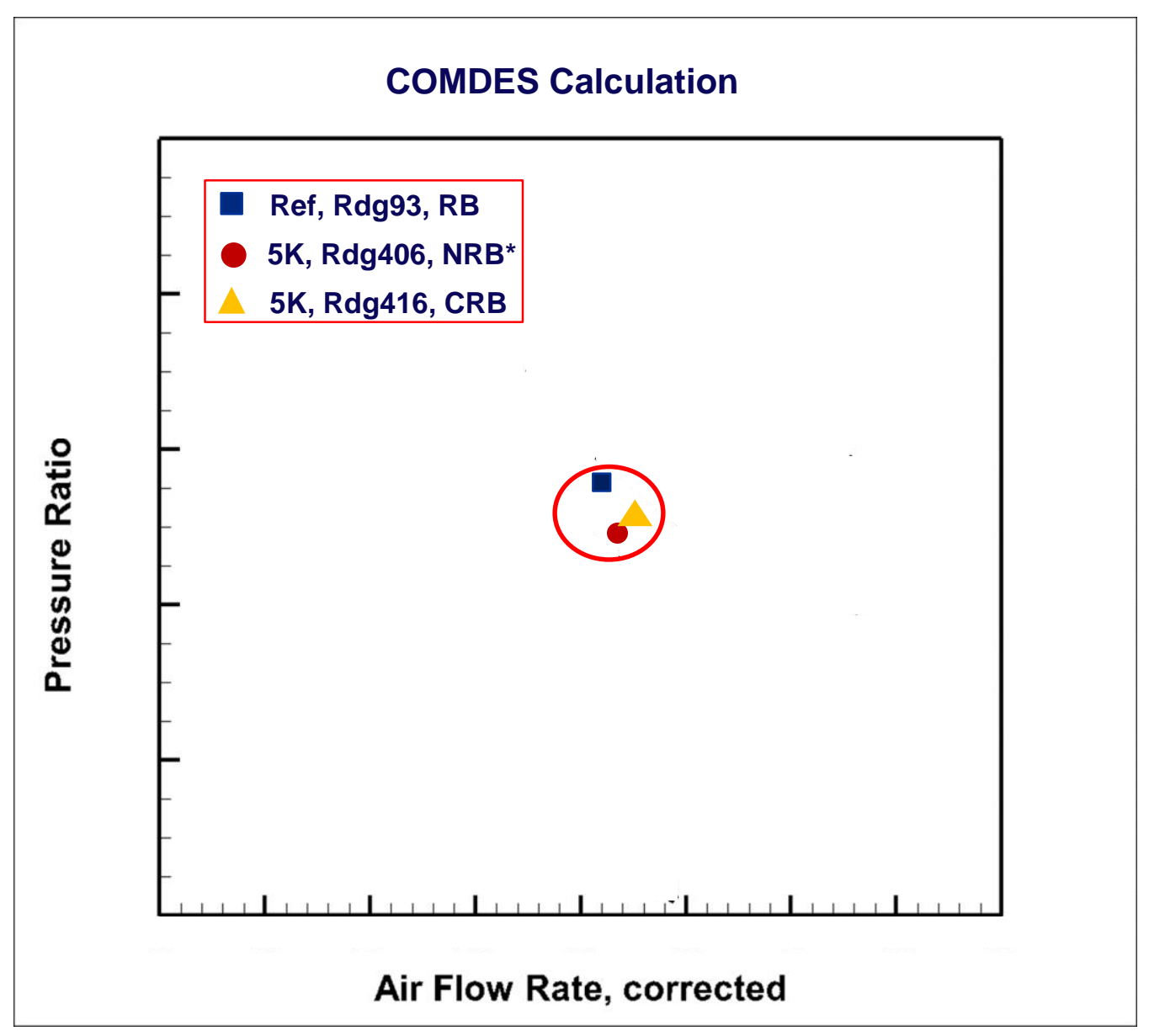

The $5 \mathrm{~K}$ cases could qualitatively simulate the Ref IC icing feature \& icing effect (RB) 


\section{Conclusion}

- A simplified approach for altitude scaling consideration has been evaluated in 2015 LF11 engine IC icing test campaign

1) It utilizes a LF01/LF11 calibrated COMDES code to determine the $5 \mathrm{~K} \mathrm{ft}$ scale conditions with similar engine IC icing risk by matching the following three icing parameters at LF11 EGV2 TE

1. local static wet bulb temperature $T_{\text {wbs }}$

2. local IC melt ratio of a prescribed smaller particle size $(5 \mu m)$

3. engine fan face $I W A R$ (i.e. the non-dimensional ice water content $=I W C / \rho_{\infty} \equiv I W C^{*} Q / \dot{m}$ ) while best maintaining similar fan-core/LPC operation characteristics

2) A parametric sweep of $I W C, M M D, T_{P L}$ and $N 1$ around each $5 \mathrm{~K} \mathrm{ft}$ scale condition to better understand both the ice accretion and engine icing effect characteristics - help evaluate how similarly the reference IC icing and icing effect features being simulated

- The videos could only provide limited IC icing characteristic evidence. Better ice shape characterization w.r.t. its effects on engine is needed

- Preliminary results showed that altitude scaling is possible for PSL to simulate the important ice accretion features and associated icing effects on engine performance.

\section{but there are still areas for improvement and further evaluation}




\section{Discussion}

In particular, special considerations and unique test methods are needed to account for

1. Different type of ground based engine icing test facility operation limitations

- Altitude vs Sea Level

- Direct Connect (fan face) vs Blow Through (free stream)

2. A new engine without any knowledge of potential icing event, there will be a multistep process to conduct potential engine icing test

1) Calibrate COMDES like code with the new engine performance cycle deck

2) Run COMDES + MELT like code thru the engine compression system at various engine design operation conditions over the App. $\mathrm{D}$ envelope to identify potential icing risk conditions and the critical locations inside the engine.

3) Conduct engine icing test at altitude first to verify (modify if needed) the proposed icing risk locations as code predicted and then characterize the possible adverse effects on this new engine to establish the reference baseline condition. Identify the min IWC threshold.

4) Conduct the engine icing test at sea level to simulate the reference icing features and ice effects through the process we have shown from this LF11 test. Identify the min IWC threshold

5) Recommendation: If LF11 could be repaired for operation in a sea level engine icing test facility, the test result would give us another important piece of data for evaluation

A common research engine is best suited for this kind of effort 


\section{Discussion}

In particular, special considerations and unique test methods are needed to account for

3. The possibility of running the sea level simulation too conservatively.

- The App. D provides the upper bound of possible reference IWC at altitude

- When conducting both ref and scale icing test with IWC sweep, make sure to identify the min IWC thresholds for creating the similar type of icing effect while maintaining similar engine operation setting. That should give us a reasonable empirical-based correlation for scaling IWC

- $\quad$ For this, Mazzawy has proposed to use the average convective heat transfer ratio to scale the sea level IWC value to ensure similar ice buildup at the critical point inside the engine

- This type of concern ideally requires a well-validated 3D engine icing simulation model. But this is not a short term effort can deliver

- Current accepted method for showing compliance is the comparative analysis which by definition is leaning on the conservatism for safety concern. But the latest data suggests it is not enough 